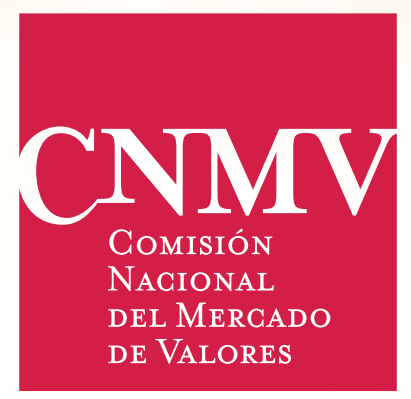

On the role of transparency in the ABS secondary market Ramiro Losada 



\section{On the role of transparency in the ABS secondary market}

Ramiro Losada López 
Ramiro Losada López pertenece al Departamento de Estudios, Estadísticas y Publicaciones de la Comisión Nacional del Mercado de Valores.

Las opiniones expresadas en este documento reflejan exclusivamente la opinión del autor y no deben ser atribuidas a la Comisión Nacional del Mercado de Valores.

La Comisión Nacional del Mercado de Valores, al publicar esta serie, pretende facilitar la difusión de estudios que contribuyen al mejor conocimiento de los mercados de valores y su regulación.

La Comisión Nacional del Mercado de Valores difunde la mayoría de sus publicaciones a través de la red INTERNET en la dirección www.cnmv.es

(C) CNMV. Se autoriza la reproducción de los contenidos de esta publicación siempre que se mencione su procedencia.

ISBN: $978-84-87870-95-8$

Depósito Legal:

Maqueta e imprime: Composiciones Rali, S.A. 


\section{Abstract}

As a consequence of the subprime crisis, a debate about the convenience of transparency enhancement in financial markets has been put forward by the securities regulators. In this paper, it is shown that under transparency, on the one hand, market makers' bid-ask spreads are lower and depth is higher in the ABS secondary market. On the other hand, the lower bid-ask spreads enjoyed by market makers reduces the number of market makers. However, introducing transparency in this market is social-welfare improving, providing the costs of implementing it are not excessively high (it could be necessary to create an information platform to spread information) and the remaining market makers buy and sell all types of ABS bonds: RMBS, CMBS, CDO, etc. This last condition guarantees that competition among market makers is kept at the same level as under an opaque ABS secondary market.

Keywords: bond markets, transparency, financial regulation.

JEL Classification: G15, G18. 



\section{Table of contents}

2.1 The model when the ABS secondary market is transparent 13

$\begin{array}{ll}2.2 & \text { Indifferent investors }\end{array}$

3 Competition among market makers $\quad 17$

\begin{tabular}{lll}
\hline $3.1 \quad$ Price competition & 17
\end{tabular}

\begin{tabular}{lll}
3.1 & Price competition & 17 \\
\hline
\end{tabular}

$\begin{array}{ll}3.2 & \text { Equilibrium price in the ABS market for sellers }\end{array}$

\begin{tabular}{lll}
\hline $3.3 \quad$ Number of market makers in the ABS market & 19
\end{tabular}

3.3 Number of market makers in the ABS market 19

\begin{tabular}{llr}
\hline 3.4 & Comparative statics & 20
\end{tabular}

4 The effect of transparency on the ABS market 23

4.1 Comparison of the results from the competition of market makers under a transparent and an opaque ABS market

4.2 The impact of transparency on Social Welfare 25

5 Conclusions 27

References

$\begin{array}{llr}\text { A } & \text { Appendix } & 31\end{array}$

\begin{tabular}{lll}
\hline A.1 Proof Lemma 1 & 31
\end{tabular}

\begin{tabular}{lll} 
A.1 Proof Lemma 1 & 31 \\
\hline
\end{tabular}

\begin{tabular}{llr}
\hline A.2 Proof Proposition 1 & 33
\end{tabular}

\begin{tabular}{llr}
\hline A.3 Proof Lemma 2 & 34
\end{tabular}

\begin{tabular}{llr} 
A.3 & Proof Lemma 2 & 34 \\
\hline
\end{tabular}

$\begin{array}{llr}\text { A.4 Proof Proposition } 2 & 36\end{array}$

$\begin{array}{llr}\text { A.5 } & \text { Proof Proposition } 3 & 38\end{array}$

$\begin{array}{llr}\text { A.6 Proof Proposition } 4 & 39\end{array}$ 



\section{Introduction}

There is a consensus that the recent market turmoil particularly affected the primary and secondary markets of ABS bonds. In the Report of the Financial Stability Board Enhancing Market and Institutional Resilience, published in April 2008, the Financial Stability Board recommended securities market regulators to work with market participants to study the possible scope of a comprehensive system for a post-trade transparency reporting system (price and volume) for credit instruments, such as ABS bonds traded in secondary markets.

The debate about the need for additional transparency for the secondary ABS market encompasses many dimensions, including transparency of the underlying assets, transparency of the structure of the product, firm-specific information about exposure to a specific product or asset class, trading transparency, and general information about the market. This paper focuses solely on transparency for ABS bonds in the secondary market.

The disclosure of information to market participants is understood as market transparency. The timing of information disclosure gives two different dimensions to transparency: pre-trade and post-trade transparency. Pre-trade transparency refers to order-book information regarding the size and price of prospective trading interest, such as firm quotations in representative size, and resting limit orders. Pre-trade market transparency can be very difficult to achieve in markets where there is no mechanism to consolidate the quotes and make them accessible to investors. However, other markets like equity markets have an electronic platform which is publicly available.

Post-trade transparency refers to the quick dissemination of past trade price and volume of completed transactions for that security. Once again, the presence of an electronic platform would facilitate the transmission of public information for traders.

Several institutions, like CESR or IOSCO, confirm their view that the lack of posttrade transparency is not considered to be the key reason behind the difficulties experienced in the bond markets during recent months. ${ }^{1}$ Nor do they believe that additional post-trade transparency would be able to solve the different problems as a singular measure. However, in combination with other measures, CESR believes that additional post-trade transparency would be able to contribute to improving current market conditions in the bond markets. In addition, the Leaders of the Group of

1 CESR stands for the Committee of European Securities Regulators. IOSCO is the International Organization of Securities Commissions. 
Twenty stated the following: We will strengthen financial market transparency, including by enhancing disclosure on complex financial product [...]. In Europe, the Member States of the European Union have the option under recital 46 of MiFID to extend transparency requirements to bond markets.

Regarding ABS bond market, the buy-side participants are supportive of increased post-trade transparency. They expressed the view that increased transparency would assist them in valuing these products, and in general lead to an improvement in price discovery and liquidity.

In contrast, sell-side participants raised concerns. One of their primary concerns is that the non-standardized, complex and illiquid nature of ABS bonds would make meaningful price comparability difficult or impossible. In their view, publishing details of distressed sales might even result in an increase in volatility, a loss of confidentiality and a further downturn of the market. They also raised concerns about the perceived high cost of implementing such a post-trade transparency regime.

In 2002, the Trade Reporting and Compliance Engine (TRACE) was set up in the United States. This system was created to provide post transparency to corporate bonds in the United States. As part of TRACE's remit, independent economists were commissioned to test the effects of transparency on corporate bond liquidity. The paper by Goldstein, Hotchkiss and Sirri (2007) found that increased post-trade transparency has a neutral or positive effect on market liquidity. Further academic studies (Hendrik B, Maxwell W and Venkataraman K. (2006), Edwards A., Lawrence E. and Piwowar M. (2007a) and Edwards A., Lawrence E. and Piwowar M. (2007b)) suggest that trade execution costs for institutional transactions in corporate bonds reduced after the introduction of transaction reporting for corporate bonds through TRACE.

It is unclear to what extent TRACE experience is one-to-one transferable to ABS bonds. There are significant differences between corporate bonds and ABS bonds, in terms of the market structure, degree of standardization and investor behavior. It should also be noted that empirical studies of the impact of TRACE were carried out in a much different market environment.

The theoretical economic literature about transparency in financial markets has been mainly devoted to equity markets. This literature on price transparency yields mixed predictions on the effect of changes in transparency (see O'Hara (1997), Madhavan (2000), de Frutos and Manzano (2002) and Bias et al. (2005)). Some argue that introducing price transparency to equity markets will improve pricing efficiency and competition, leading to lower bid-ask spreads. Others contend that transparency will increase market makers' costs of providing liquidity, leading to less dealer participation, less competition, less liquidity, and ultimately higher transaction costs.

The aim of the paper is to provide an answer about the appropriateness of promoting transparency in the ABS secondary market. In particular, what will be investigated is the impact of introducing market transparency in the competition among market makers as well as the impact that transparency has on the welfare of investors.

This paper considers the special characteristics of this market. It turns out that market makers sell ABS bonds with different characteristics (they are backed by different 
assets) but which give the same credit quality, usually AAA, to investors. These different bond characteristics mean that market makers do not sell homogeneous bonds to final investors. This, and the fact that one sole market maker often trades a bond, may mean that the ABS bond market is far from being perfectly competitive. ${ }^{2}$ Thus, this is the first paper that analyzes the introduction of transparency in a financial market where market makers compete in an environment of monopolistic competition.

The remainder of the paper is organized as follows. Section 2 presents the model and describes investors, bond buyers and market makers in a set up where there is transparency in the ABS secondary market. Section 3 analyzes the outcome of competition among market makers in the set-up presented in section 2. Section 4 compares the outcomes of competition among market makers under transparency with the outcomes under opacity. Finally, section 5 lays out the conclusions. 



\section{The model}

\subsection{The model when the ABS secondary market is transparent}

This model is based on the one presented in Losada (2009), where an opaque market structure for the ABS secondary market is analyzed. The economy that is envisioned consists of two types of securities. The analysis focuses on ABS bonds with the same rating and an outside asset with the same rating which represents other bond markets. It is considered that in the market for ABS there are market makers which buy bonds from bond sellers and sell bonds to bond buyers (investors). Bond sellers and investors do not trade directly with each other. Market makers have decreasing average costs and are involved in a monopolistic competition where bonds are differentiated. Investors have the option of investing in ABS bonds or in other alternative securities according to their preferences, prices and the distribution of ABS bonds in the product space. The population of investors is normalized to one. The identity of market makers is commonly known. Investors enjoy full transparency in this market.

Each investor has a most-preferred ABS bond $b^{*}$. A bond $b$ different from the mostpreferred specification is valued lower according to preferences in product space $U\left(b, b^{*}\right)$. The product space of the ABS market is taken to be the unit-circumference of a circle. Investors are located uniformly along the circumference. These assumptions allow a market equilibrium with identical prices by equally-spaced bonds. Eliminating technical difficulties makes it simpler to analyze the qualitative equilibrium properties of the model. The model reflects the fact that although ABS bonds are created with the same credit risk -they are usually rated AAA- their prices can evolve in different ways in the long run. ABS bonds are found in the market backed by a group of mortgages (MBS bonds), or by a group of corporate bonds (CDO bonds), or by a group of CDO bonds (CDO squared bonds), etc. ${ }^{3}$ Thus, given the same initial credit risk, there are investors who prefer to invest in an ABS bond backed by mortgages than in an ABS bond backed by corporate bonds while other investors prefer the opposite.

Investors incur in a search cost, $\gamma$, in order to know the ABS bonds' locations and prices. This search cost does not depend on the number of market makers who operate in the market. In bond markets where there is transparency, information about bond trading is made public through financial information platforms or

3 In the book by Fabozzi F. and Choudhry M. (2004), The Handbook of European Structured Financial Products, Willey Finance, there is a detailed description of different ABS bonds backed by different pools of assets. 
through institutional platforms like TRACE in the USA. ${ }^{4}$ In this paper, it is assumed that the post trade information is spread through the financial information platforms. These platforms give market makers bond prices in real time and they are costly for investors. However, investors pay a flat price for the amount of information they get from these kinds of platforms.

If there are $L$ differentiated bonds at price $p_{i}$ and location $b_{i}$, an investor who decides to buy an ABS bond and whose most preferred specification is $b^{*}$ will obtain an utility:

$$
v-\gamma-t\left|b_{i}-b^{*}\right|-p_{i}
$$

By assumption, $\gamma$ is always bounded in the interval $\left[v-k-q-\frac{5 t}{6 L}, v-k-q\right]$, where $q$ is the price at which market makers buy ABS bonds and $k$ represents the other marginal costs a market maker incurs when he trades in the ABS market. ${ }^{5}$ Parameter $t$ reflects how different investors perceive the available ABS bonds. The utility investors receive from the alternative bonds is normalized to zero.

Each market maker sells at least one of the $L$ ABS bonds available in the market. For simplicity, it is assumed that each market maker sells the same number of ABS type of bonds, $L / N$, where $N$ is the total number of market makers which operate in the ABS bond market. ${ }^{6}$ Any of the $L$ bonds is sold by two or more market makers. ${ }^{7}$ Also for simplicity, it is assumed that market makers do not sell bonds that are consecutively located on the circumference. If a market maker sells ABS bonds that are consecutively located in the investor's preference circle, he is willing to charge higher prices to investors because in some types of ABS bonds he only competes with himself. ${ }^{8}$

Bond sellers are considered to be price takers. Investors in the ABS markets almost always follow a buy and hold strategy. Thus, in most cases bond sellers sell their bonds when they are in a liquidity shortage or when they rebalance their portfolio.

The ABS market is modelled as the result of a game composed by the following stages:

4 The most popular financial information platforms are Bloomberg and Thomson Reuters. TRACE stands for the Trade Reporting and Compliance Engine. TRACE is the post trade information platform for Corporate Bonds in the USA. This platform was created in 2002 to meet the post trade requirements demanded by the Securities and Exchange Commission.

5 The variable $k$ could be interpreted as the opportunity costs market makers have from the moment when they buy a bond until they sell it. When there is transparency, it could be assumed that market makers have an extra marginal cost as they have to meet compliance requirements each time they sell a bond.

6 As the reader could easily deduce, in many of the cases they could consider $L / N$ is not an integer. In those cases it could be interpreted that the demand of each investor for one of the ABS bonds is satisfied by the $N$ market makers with equal probabilities.

$7 \quad$ Spulber (1993) shows a set-up where many different market makers try to sell the same asset. In the ABS market it is very common that only one market maker sells a bond. This article and the companion paper Losada (2009) can be considered as complementary to Spulber (1993).

8 In Losada (2009), a set-up is analyzed that relaxes the assumption that market makers only sells bonds that are not consecutively located. Although the set-up might be more realistic, it is shown that generalizing the model adds more complexity to the model whereas it would not change the qualitative results. 
1. $\quad N$ market makers decide to enter into the ABS market to buy and sell bonds.

2. Original holders of bonds sell the bonds to market makers. The bond sellers behave as price takers.

3. When market makers hold the bonds, they compete in prices. Investors decide whether to buy a unit of their most preferred ABS bond given the prices set by market makers or to buy a bond from an alternative bond market.

At this stage, it is important to point out that a transparent ABS market is assumed. This means that investors obtain information about prices and bond characteristics under anonymity and market makers cannot infer the location of the investor's preferences on the circumference. Under this assumption, market makers price discrimination is avoided.

\subsection{Indifferent Investors}

In this set-up, there are $2 L$ indifferent investors. There are two different indifferent investors for each available bond in the ABS market as there are investors who finally choose not to buy any of the ABS bonds. So, the indifferent investors hold the following conditions:

1. There must be investors who are willing to buy any of the available ABS bonds. This means that:

$$
v-\lambda-t\left|b_{i}-b^{*}\right|-p_{i} \geq 0
$$

At this stage, it is assumed that $\delta$ investors is the proportion of investors that do not buy any of the $L$ ABS available bonds. The reader should notice that the total demand for ABS is $1-\delta$.

2. Among the investors that are willing to buy ABS bonds, the indifferent ones are located at a distance of $b_{i}, i=1, \ldots . . . . ., 2 L$ from the location of each of the $L$, where $b_{i}$ is determined by:

$$
p_{i}+t b_{i}=p_{j}+t\left(\left(\frac{1}{L}-\delta\right)-b_{i}\right)
$$

or equivalently:

$$
b_{i}=\frac{1}{2}\left(\frac{1}{L}-\delta+\frac{\left(p_{j}-p_{i}\right)}{t}\right)
$$

In determining the indifferent consumers, the assumption that the ABS market is transparent is particularly important. Market makers cannot know the location of investors on the circumferences when they search for ABS bond prices. If market makers became aware of the location of investors preferences, they would be willing to discriminate among investors by offering them different prices for the same ABS bond. 
Figuring out the indifferent investors makes it possible to work out the demand for each of the ABS bonds. So, the demand for each of the ABS bonds is twice the position on the circumferences of the indifferent investor:

$$
D_{i}\left(p_{j}, p_{i}\right)=\frac{1}{L}-\delta+\frac{\left(p_{j}-p_{i}\right)}{t} i=1, \ldots ., L
$$

and where $j \neq i$ are the nearest bonds to bond $i$. 


\section{Competition among market makers}

\subsection{Price competition}

In this section, the game presented in the previous section is solved and analyzed. To solve the game, the backward induction procedure is used to look for the Subgame Perfect Nash Equilibrium. So, at the price competition stage, parameters $q$ and $N$ are fixed. By assumption, market makers do not hold ABS bonds to sell that are consecutively located on the circumference. Hence, market makers solve the following maximization problems for each of the bonds: 9

$$
\begin{gathered}
\max _{p_{i}} \Pi_{i}=\left(p_{i}-k-q\right)\left(\frac{1}{L}-\delta+\frac{\left(p_{j}-p_{i}\right)}{t}\right), i=1, . ., L \text { and } j \neq i \\
\text { s.t. } \delta=\frac{1}{L}-\frac{2\left(v-\lambda-p_{i}\right)}{t}, \delta \geq 0,
\end{gathered}
$$

where $j$ is the nearest bond on the circumference to $i$ and $f$ is the fixed cost a market maker pays to be able to trade in the ABS market. When solving the optimization problem only the case where $\delta>0$ is considered. This case is the closest to reality where ABS bonds as well as the alternative AAA bonds have some trading activity.

Substituting the constraint in the objective function and taking the derivative with respect to $p_{i}$ leads to:

$$
\frac{\partial \Pi_{i}}{\partial p_{i}}=2\left(v-\lambda+p_{j}-3 p_{i}\right)-3\left(p_{i}-k-q\right)=0, i=1, \ldots ., L
$$

From the system of equation above and by symmetry among the $L$ ABS bonds, equilibrium prices are: ${ }^{\circ}$

$$
p_{1}^{T}=p_{2}^{T}=\ldots \ldots . . .=p_{N}^{T}=\frac{2(v-\lambda)+3(k+q)}{5}
$$

The equilibrium prices are above the cost market makers have paid, so that market makers enjoy market power. The market makers mark-up is:

$$
p^{T}-k-q=\frac{2(v-\lambda-k-q)}{5} \text {. }
$$

9 In the case where $L / N$ is not an integer, there is a bond that is not exclusively owned by a market maker. It is assumed that the price of the bond is set by a market maker who does not have either of the two closest bonds to it.

10 The second order condition of the profit function of each of the bonds trivially satisfies the condition to be concave. Later in the paper, in the proof of Lemma 1, it is proved that the profit functions are concave with respect to $p_{i}$. 
At this stage, the equilibrium price and mark up do not depend upon $t$. The parameter reflects how different investors think bonds are among themselves. This result could be surprising when it is compared with the traditional model of horizontal differentiation by Salop (1979) where prices and mark-ups depend critically on $t$. This happens because in this model there is an alternative to buying ABS bonds, that is buying a bond from another alternative bond market. Market makers take into account the existence of the alternatives which do not allow them to fully profit from the existing differentiation among ABS bonds when they price their bonds.

If the equilibrium price $p^{T}$ is substituted in the market maker's optimization problem constraint, we obtain the proportion of bonds that investors buy in the ABS market:

$$
d^{T}=\frac{6(v-\lambda-k-q)}{5 t} .
$$

The condition that $\lambda \in\left[v-k-q-\frac{5 t}{6 L}, v-k-q\right]$ guarantees that $d^{T} \in\left[0, \frac{1}{L}\right]$.

\subsection{Equilibrium price in the $\mathrm{ABS}$ market for sellers}

The previous stage in the resolution of the game gave the demand for each of the bonds, $d^{T}$. In the model, it is assumed that ABS bond sellers are price takers. This assumption tries to pick up the fact that most sellers of these types of bonds take their bonds to the market for liquidity reasons. So, it is assumed that the supply function of bonds is:

$$
s=\frac{q-r}{\gamma}
$$

where $r$ is a reservation value. None of the ABS bond holders will take their bond to the market if the price $q$ is below $r$. Parameter $\gamma$ is the supply function quantity sensitivity to the market price that sellers receive for the bonds.

The equilibrium price is determined through the equilibrium condition $d^{T}=s$ :

$$
q^{T}=\frac{6 \gamma(v-\lambda-k)+5 t r}{6 \gamma+5 t}, q^{T} \in\left[r, r+\gamma \frac{1}{L}\right]
$$

The price that is paid to bond sellers is determined through a crossover between the market power that market makers enjoy, represented by $t$, and the willingness of the bond sellers to offer their bonds, $\gamma$. It is important to notice that as market makers enjoy more market power in the final market they also enjoy a buying price, $q$, closer to the bond seller's reservation value, $r$. This happens because as $t$ is higher the ABS bond demand is lower due to competition from other bond markets (specially public debt markets). However, bond sellers enjoy higher prices than $r$ when $v-\lambda-k$ is high. As $v-\lambda-k$ rises, the demand for ABS bonds is higher in the final market because they face less competition from the other bond markets.

The result of price competition among market makers and the determination of the equilibrium price that is paid to bond sellers allow us to determine the equilibrium ABS bond price paid by the investors of the model and the depth of the ABS market: 
Lemma 1 If it is considered that in the ABS and alternatives bond market there is trading activity, the market makers charge investors of ABS bonds the price:

$$
p^{T}=\frac{(6 \gamma+2 t)(v-\lambda)+3 t(k+r)}{6 \gamma+5 t}, p^{T} \in\left[k+r, k+r+(\gamma+t) \frac{1}{L}\right]
$$

The proportion of investors who buy any of the $L$ ABS bonds is:

$$
d^{T}=\frac{6(v-\lambda-k-r)}{6 \gamma+5 t}, d^{T} \in\left[0, \frac{1}{L}\right] .
$$

Proof: See Appendix

The result of lemma 1 makes the equilibrium profit for each of the market makers:

$$
\begin{gathered}
\Pi_{n}^{T}=\frac{L}{N}\left(p^{T}-k-q^{T}\right) d^{T}-f \Rightarrow \\
\Rightarrow \Pi_{n}^{T}=\frac{L}{N} \frac{t}{3}\left(\frac{6(v-\lambda-k-r)}{6 \gamma+5 t}\right)^{2}-f \Rightarrow \\
\Rightarrow \Pi_{n}^{T}=\frac{L}{N} \frac{t}{3} d^{T 2}-f, n=1, \ldots . ., N, \Pi_{n}^{T} \in\left[0, \frac{t}{3 N L}-f\right] .
\end{gathered}
$$

It is important to remember that these equilibrium prices and proportion of investors buying in the ABS market are based on assumptions that make market makers behave symmetrically. In a more realistic set-up where market makers are not located symmetrically or where they do not share the same operational cost, equilibrium prices would vary from one market maker to another. ${ }^{11}$

Equilibrium proportions of ABS investors as well as the equilibrium prices in the final market do not depend on the number of bonds sold, $L$. This result differs from Salop (1979) where prices and quantities depend on the number of products sold in the market. ${ }^{12}$ Given the competition from the other bond markets, market makers offer investors as many different bonds as they can from the primary market as it matches better to investor preferences. With this strategy, market makers can better face the competition from other bond markets.

\subsection{Number of market makers in the ABS market}

In the last stage of the resolution of the game, and given the results in the previous stages, we can work out the number of market makers that operate in the ABS market:

Proposition 1 If $\gamma<v-k-r-\frac{6 \gamma+5 t}{6 L}$, the number of market makers is:

$$
N^{T} \text { such that } N \geq 2
$$

11 The assumption that market makers have different operational costs or even different perceptions of the value of a financial asset is justified by following Ho and Stoll (1983) and Biais (1993), and by assuming that risk-averse dealers have different inventories and different expected values of an asset.

12 In Salop (1979), the symmetric price and quantity are $p^{T}=c+\frac{t}{L}$ and $d^{T}=\frac{1}{L}$, where $c$ is the marginal cost of the product sold. 
such that $N$ is the integer that satisfies:

$$
\frac{L}{N} \frac{t}{3}\left(\frac{6(v-\lambda-k-r)}{6 \gamma+5 t}\right)^{2}-f=0 .
$$

Proof: See Appendix

It is considered that market makers compete in a market with free entry. Therefore, market makers will enter into the ABS market up to the number that makes the profit of each market zero or close to zero. If a new market maker entered the ABS market when there are already $N^{\top}$ market makers, all market makers would make a negative profit.

\subsection{Comparative statics}

So far, the equilibrium buying and selling prices and the equilibrium proportion of investors that buy bonds in the ABS market have been presented. It may be interesting to show how these equilibrium variables behave to changes in the independent variables of the model, $(L, v, k, r, t, \gamma, \lambda)$.

So, it is straightforward that $p^{T}, q^{T}$ and $d^{T}$ are positive with respect to $v . p^{T}$ is also increasing with respect to $k$ and $r$. However, $q^{T}$ is decreasing with respect to $k$ and increasing with respect to $r, d^{\top}$ is decreasing in both variables. When $v$ gets higher the price charged to investors and the buying price, as well as the proportion of investors that buy ABS bonds, are also higher. This happens because more investors find buying ABS bonds more attractive than buying in other bond markets. As the proportion of buyers is higher, market makers can charge higher prices without losing investors. The buying price increases as a consequence of the $d^{T}$ behavior.

The relationship between $d^{T}$ and the variables $t$ and $\gamma$ is also clear. $d^{T}$ has negative derivatives with respect to $t$ and $\gamma$. However, the relationship between $p^{T}$ and the variables $t$ and $\gamma$ is not so clear at first sight. With the derivatives of $p^{T}$ and $q^{T}$, it can be proved that:

$$
\begin{aligned}
& \frac{\partial p^{T}}{\partial t}<0, \frac{\partial q^{T}}{\partial t}<0, \\
& \frac{\partial p^{T}}{\partial \gamma}>0, \frac{\partial q^{T}}{\partial \gamma}>0 .
\end{aligned}
$$

It is found that $p^{T}$ is decreasing with $t$. This happens because as $t$ gets higher less investors find buying in the ABS market attractive. Market makers must lower the price to buy in the ABS market. Market makers must lower the price to face higher competition from the other bond markets. This fact also has important consequences in the behavior of $d^{T}$ and $q^{T}$ with respect to $t$. Although market makers charge lower prices to investors as $t$ gets higher, investors prefer to switch to other alternative bond markets. A lower proportion of investors, $d^{T}$, buy a bond in the ABS market. A lower proportion of investors in the final market results in a lower demand of market makers when they meet bond sellers in the competitive market. The immediate consequence of lower demand is that the bond sellers receive a lower price, $q^{T}$. 
It is also found that $p^{T}$ is increasing with respect to $\gamma$. This happens because as $\gamma$ increases, ceteris paribus, sellers of bonds in the competitive market receive a higher price $q^{T}$. Market makers end up reflecting the increase in the price paid to bond sellers due to an increase in $\gamma$ raising their final price to investors. As $p^{T}$ increases with $\gamma$, final investors find buying ABS bonds less attractive, which means that the proportion of investors, $d^{T}$ decreases with $\gamma$.

From the behaviour of $d^{T}$, we can infer the behavior of market makers' profits with respect to the independent variables of the model, as $\Pi_{n}^{T}=(L / N) t\left(d^{T}\right)^{2}-f$. Nevertheless, the reasons that backed that behavior for the variables $t$ and $\gamma$ are not evident. For these variables are:

$$
\frac{\partial \Pi_{n}^{T}}{\partial t}<0, \frac{\partial \Pi_{n}^{T}}{\partial \gamma}<0
$$

On the one hand, with the equilibrium price mark-up, $p^{T}-q^{T}-k$, the market makers set is increasing with respect to $t$. On the other hand, the proportion of investors that decide to buy ABS bonds is decreasing with respect to $t$. However, the second derivative of the markup with respect to $t$ is always lower than the second derivative of $d^{T}$ with respect to $t$.

At the end of this appendix, the reader can find graphs with examples that show the relationship between $p^{T}, q^{T}, d^{T}$ and $\Pi_{n}^{T}$ with respect to $t$ and $\gamma$ shown above. ${ }^{13}$

13 In these graphs, it is assumed that there are a fixed number, $N$, of market makers. 



\section{The effect of transparency on the ABS market}

\subsection{Comparison of the results from the competition of market makers under a transparent and an opaque ABS market}

In Losada (2009), the ABS bond market is analyzed using the same model as in the present paper but assuming that the market is opaque. In this section, a comparison is made between the outcomes from the model of this paper and the ones from the model of Losada (2009). It is assumed that the consumers' search cost and the market makers' fixed costs are equal in both models to make their outcomes comparable.

The differences between the two models are reflected in how the search cost is defined and in the way investors take the decision to buy an ABS bond under opacity. The search cost under opacity is modelled as a function of the number of market makers that operate in the market. In an opaque market, if an investor wants to buy an ABS, he asks the different market makers until he gets in touch with the market maker that owns such a bond. Moreover, in Losada (2009), it is proved that if the market is opaque, an investor who wants to buy an ABS bond has positive probability of asking all market makers. So, the investors' search cost is an increasing and convex function of the number of market makers that operate in the ABS secondary market. In the paper, that search function is defined as $\beta(N)$, where $N$ is the number of market makers.

The other difference between the two models is that investors have access to all ABS bond information about their prices and locations in the transparent market. In the opaque market, when an investor starts searching for an ABS bond, he does not know if he will finally buy the ABS bond or the alternative bond. This difference leads to market makers having a restriction in their maximization problem when the market is transparent that they do not have in the maximization problem when the market is opaque. In the former, any change in the prices a market maker sets for their bonds is immediately reflected in a variation of the number of investors that want to buy that bond. In the latter, if a market maker changes the price of a bond, an investor needs to incur a search cost to know the new price. Given these differences, the outcomes of the model when the market is opaque are:

Lemma 2 When the market makers charge investors of ABS bonds:

$$
p^{o}=\frac{2(\gamma+t)(v-\beta(N)+t(k+r)}{2 \gamma+3 t}, p^{o} \in\left[k+r, k+r+(\gamma+t) \frac{1}{L}\right] .
$$

The proportion of investors that buy each of the $L$ ABS bonds is:

$$
d^{\circ} \frac{2(v-\beta(N)-k-r)}{2 \gamma+3 t}, d^{\circ} \in\left[0, \frac{1}{L}\right] .
$$


Proof: See Appendix

Given the outcomes of the model under transparency and opacity, it can be concluded that:

Proposition 2 Under the same search costs and the same fixed costs, the market maker's profits and mark-ups are lower, whereas the market maker's buying equilibrium prices and the quantities traded are higher when the ABS secondary market is transparent.

Proof: See Appendix

These results about prices and depth in the ABS secondary markets mean that under opacity the number of market makers under free entry is:

Proposition 3 If $\beta(N)<v-k-r-\frac{2 \gamma+3 t}{2 L}$, the number of market makers is:

$$
N^{O} \text { is } N \geq 2
$$

such that $N$ is the integer that satisfies:

$$
\frac{L}{N} t\left(\frac{2(v-\beta(N)-k-r)}{2 \gamma+3 t}\right)^{2}-f=0
$$

Proof: See Appendix

In the outcomes above, it is proved that under a transparency regime, prices charged to investors would be lower in comparison with the ones under an opacity regime. Moreover, the prices bond sellers receive increase. Therefore, the mark-up that market makers enjoy is notably lower under transparency than under opacity. This implies than the number of market makers operating in the secondary ABS market is lower under transparency. It does not seem to be a good result that under transparency the number of market makers is reduced. However, as long as the market makers sell bonds that are not consecutively located, competition and prices in the final market will remain the same.

It is good to point out that these outcomes were produced under the assumption that the search costs were the same under opacity and under transparency. However, in reality, the search costs should be lower under transparency because investors have access to cheaper information. Thus, the qualitative results about buying and selling prices and market makers mark-ups should be even more robust.

From the outcomes of the model, it can be concluded that the introduction of transparency in the ABS secondary market is Social Welfare improving as the liquidity in the market is higher. With transparency, a higher depth is introduced into the market and the spreads are tighter. The results about spreads tights narrowing are in line with the empirical evidence that has emerged since the introduction of TRACE in the United States. So, Edwards et al. (2007a), Goldstein et al. (2006) and Bassemwinder et al. (2005) find unambiguous evidence that introduction of the TRACE system did significantly reduce bid-ask spreads.

The other significant result that came out from the model is that the number of market makers that operate in this market under transparency is significantly lower. 
In most models, a lower number of market markers means that the positive effect of tightening spreads by transparency would be partially offset by higher market power of market makers. This does not happen in this model as long as the remaining market makers do not sell consecutively located ABS bonds after the introduction of transparency. This result should lead to the policy recommendation that if the regulator decides to introduce transparency in the ABS secondary market, it should also introduce the condition for market makers that they must be global. They should sell all types of ABS bonds. If the regulator does not do the latter, after the introduction of transparency, the market makers will have incentives to be specialized in selling and buying a small number of types of ABS bonds.

\subsection{The impact of transparency on Social Welfare}

The social welfare function is defined as the sum of investors' and bond sellers' surplus minus market makers' fixed costs. As in the previous subsection it is assumed that under both regimes the search costs are the same, $\beta(N)=\lambda$ :

$$
W=2 L\left(\int_{0}^{\frac{1}{2} d}(v-\lambda-k-q-t y) d y+\int_{0}^{\frac{1}{2} d}(q-r-\gamma y) d y\right)-N f
$$

By working out the social welfare function we obtain:

$$
W=L\left((v-\lambda-k-r) d-\frac{1}{4}(t+\gamma) d^{2}\right)-N f
$$

The drivers of the Social Welfare function are the depth of the market and the number of market makers that operate in it. Given the depths of the market and the number of market makers under both regimes, we obtain:

Proposition 4 Under the same fixed costs for market makers and search costs for investors, the Social Welfare is higher under transparency than under opacity.

Proof: See Appendix

The reasons why this result came out are fairly straight-forward. As the depth of the market is higher under transparency and the number of market makers is lower, the gains of social welfare are higher with that regime while the fixed costs paid by market makers are lower.

As can be observed in the graphs in the appendix, the Social Welfare enhancement is higher when a transparency regime is established as $t$ is lower. As investors perceive the different ABS bonds as more homogenous, ABS bonds can compete better with other alternative bonds. When $t$ is low, investors are more sensitive to the price fall due to the shift to transparency.

This model proves that any change that improves transparency is social-welfare improving. Following the results of this model, the proposal of applying posttransparency to the ABS market provided for in recital 46 of the Markets in Financial Instruments Directive (MiFID) is social-welfare improving as far as post-transparency allows investors to make a better price formation. However, this policy recommendation has a qualification. In this model, the cost of the introduction of post-transparency 
was not considered. When the market under opacity and transparency regimes were compared, it was assumed that fixed and variable costs of market makers do not change. The introduction of post-transparency would entail implementing a system similar to the TRACE system. If that system is paid for by market makers, their fixed costs would be higher and their variable costs could also rise (there could be an increase in regulatory compliance). So, the benefits from setting post-transparency might not be as high as shown in this model. Nevertheless, if the costs of implementing post-transparency are not very high, then it should be introduced in order to improve social welfare.

Regarding the payment of the fixed costs of implementing a system to give posttransparency to the ABS secondary market, the possible positive externalities the system has in other financial agents should be taken into account. The current crisis has proved that post-transparency information on ABS bond prices is a necessary output for many financial agents -mutual and pensions funds, banks, financial regulators, analysts, etc.- in order to improve the accuracy of their valuation of their or others' instruments and the risks that these instruments entail. 


\section{Conclusions}

In this paper the effects of introducing transparency in the ABS bond market have been analyzed. A model was proposed where investors have heterogeneous preferences about ABS bonds with the same rating and where there is transparency in the market. This model was compared with the one in Losada (2009), where the model is the same but there is a lack of transparency.

In the paper, it is shown that the introduction of transparency is social-welfare improving. If both regimes are compared, the market makers' bid-ask spreads of bonds tighten and the depth of the ABS market is higher under transparency than under opacity. In the opaque market, when an investor starts searching for an ABS bond, they do not know if they will finally buy the ABS bond or the alternative bond. On the contrary, in a transparent market, any change in the prices a market maker sets for their bonds is immediately translated in a variation in the number of investors that want to buy that bond. This means that market makers enjoy less market power under transparency due to investors' higher price elasticity. As a direct consequence of the market makers' lower selling prices, the depth in the market and the market markers bonds' buying prices are higher.

Given the same fixed costs under both regimes, the lower bid-ask spreads that market makers enjoy under transparency have a negative effect in market makers' profits. This result has a direct implication: the number of market makers that operate in the ABS secondary market is lower under transparency than under opacity. Nevertheless, a lower number of market makers does not change the level of competition in the market as long as they buy and sell all type of ABS bonds: RMBS, CMBS, CDO, CLO, etc. This last point arises because this way the market makers are unable to find a niche in the market where they could enjoy big market power.

The Reports by IOSCO (2009) and CESR (2009) advocate an increase in the transparency of the ABS markets. The results from the comparison between both regimes in this paper backs up the arguments presented by IOSCO and CESR that there is a need to introduce post-transparency in this market. In the European Union, an increase in transparency could easily be implemented as recital 46 of MiFID allows the Member States to establish post-transparency in non-equity markets.

However, an increase in the post-transparency of the ABS market could require the construction of a platform similar to TRACE (the platform built in the United States to spread the post trade information of corporate bonds). This means that the introduction of transparency can involve new fixed costs for market makers. As the introduction of transparency means less income for market makers, an excessive increment in the fixed cost could make market makers drop out the market. Thus, it is important to set up transparency at a cost that could be assumed by market makers. 
The important positive externalities for other financial agents should also be taken into account when setting up transparency. These agents -mutual funds, banks, analysts, etc.- could use the information spread by the transparency to value their ABS bonds or others' more accurately as well as to better evaluate better the risks these instruments entail. Thus, these financial agents should bear part of the cost of establishing transparency in the ABS secondary market. 


\section{References}

Bassemwinder, H., Maxwell W. and Venkataraman K. (2005). Market transparency and institutional trading costs. University of Utah. Working Paper.

Biais, B. (1993). Price formation and equilibrium liquidity in fragmented and centralized markets. Journal of Finance, 48, pp. 157-186.

Biais, B., Glosten L. and Spatt C. (2005). Market microstructure: a survey of microfundations, empirical results, and policy implications. Journal of Financial Economics, 82, pp. 251-288.

CESR (2009). Transparency of corporate bond, structured finance product and credit derivative markets. Ref CESR/o9-348.

de Frutos, M.A. and Manzano C. (2002). Risk aversion, transparency and market performance. Journal of Finance, vol 57, pp. 959-984.

Edwards A., Lawrence E. and Piwowar M. (2007a). Corporate bond market transaction costs and transparency. Journal of Finance, 62, pp. 1421-1451.

Edwards A., Lawrence E. and Piwowar M. (2007b). Corporate bond market transparency: liquidity concentration, information efficiency and competition. Securities and Exchange Commission, Office of Economic Analysis.

Fabozzi F. and Choudhry M. (2004). The handbook of European Structured Financial Products. Willey Finance.

Goldstein M., Hotchkiss E. and Sirri E. (2007). Transparency and liquidity: a controlled experiment on corporate bonds. Journal of Financial Studies, 20, pp. 235-273.

Hendrik B, Maxwell W and Venkataraman K. (2006). Market transparency, liquidity externalities, and institutional trading costs in corporate bonds. Journal of Financial Economics, 82, pp. 251-288.

IOSCO (2009). Transparency of strucutured finance products. Available at http://www. iosco.org/library/pubdocs/pdf/IOSCOPD306.pdf.

Losada, R. (2009). Could regulation of the ABS market improve social welfare?. Monografía n. ${ }^{\circ}$ 37, Comisión Nacional del Mercado de Valores. Available at http:// www.cnmv.es.

Madhavan, A. (2000). Market microstructure: A survey. Journal of Financial Markets, 3, pp. 205-208. 
O'Hara, M. (1997). Market microstructure theory. Basil Blackwell, Cambridge, MA.

Pagano, M. and Roell Ailsa. (1996). Transparency and liquidity: a comparison of auction and dealer markets with informed trading, Journal of Finance, vol 51, pp. 579-611.

Salop, S.C. (1979). Monopolistic competition with outside goods. The Bell Journal of Economics, 10, pp. 141-156.

Spulber, D.F. (1996). Market making by price-setting firms. Review of Economics Studies, 63, pp. 559-580.

Stoll, H.R. (1985). Alternative views of market making. In Amihud, Y. et al (eds.), Market making and the changing structures of the securities industries (Lexington: Lexington Books).

Yin X. (2005). A comparison of centralised and fragmated markets with costly search. Journal of Finance, vol. 6o, pp. 1567-1590. 


\section{A Appendix}

\section{A.1 Proof Lemma 1}

At the first stage, market makers maximize the following profit function for each of the ABS bonds they sell:

$$
\begin{gathered}
\Pi_{i}=\left(p_{i}-k-q\right)\left(\frac{1}{L}-\delta+\frac{\left(p_{j}-p_{i}\right)}{t}\right), i=1, \ldots, L, j \neq i \\
\text { s.t. } \delta=\frac{1}{L}-\frac{2\left(v-\lambda-p_{i}\right)}{t}
\end{gathered}
$$

Substituting the constraint in the objective function and taking the derivative with respect to $p_{i}$, the first order condition becomes:

$$
\frac{1}{t}\left(2(v-\lambda)+\left(p_{j}-3 p_{i}\right)-3\left(p_{i}-k-q\right)\right)=0
$$

By symmetry and working out the first order condition we obtain:

$$
p^{T}=\frac{2(v-\lambda)+3(k+q)}{5}
$$

If the second order condition is taken to the maximization problem, we obtain:

$$
-\frac{6}{t}<0
$$

Therefore, $p^{T}$ are the prices that maximize the profit functions for each of the ABS bonds.

Substituting $p^{T}$ in the maximization problem constraint, we obtain:

$$
\delta=\frac{1}{L}-\frac{6(v-\lambda-k-q)}{5 t}
$$

and the demand for ABS bonds from investors is at this stage:

$$
d^{T}=\frac{6(v-\lambda-k-q)}{5 t} \text {. }
$$

Given $d^{T}$ and given the supply function of bonds:

$$
s=\frac{q-r}{\gamma},
$$

the equilibrium price that the ABS bond sellers receive can be worked out:

$$
q^{T}=\frac{6 \gamma(v-\lambda-k)+5 t r}{6 \gamma+5 t} .
$$


Substituting $q^{T}$ in $p^{T}$ and $d^{T}$, we obtain the equilibrium final price and demand for the ABS bonds:

$$
\begin{gathered}
p^{T}=\frac{(6 \gamma+2 t)(v-\lambda)+3 t(k+r)}{6 \gamma+5 t}, \\
d^{T}=\frac{6(v-\lambda-k-r)}{6 \gamma+5 t} .
\end{gathered}
$$

As by assumption $\lambda$ could be binding its boundary, equilibrium price and demand could be also binding their boundaries:

$$
p^{T} \in\left[k+r, k+r+(\gamma+t) \frac{1}{L}\right], d^{T} \in\left[0, \frac{1}{L}\right] .
$$




\section{A.2 Proof Proposition 1}

The profit function of each of the market makers is:

$$
\Pi_{n}=\frac{L}{N}\left(p^{T}-q^{T}-k\right) d^{T}-f, n=1, \ldots ., N .
$$

where

$$
\begin{gathered}
p^{T}=\frac{(6 \gamma+2 t)(v-\lambda)+3 t(k+r)}{6 \gamma+5 t}, \\
d^{T}=\frac{6(v-\lambda-k-r)}{6 \gamma+5 t} .
\end{gathered}
$$

and

$$
q^{T}=\frac{6 \gamma(v-\lambda-k)+5 t r}{6 \gamma+5 t} .
$$

Substituting $p^{T}, d^{T}$ and $q^{T}$ in the profit function, we obtain:

$$
\Pi_{n}=\frac{L}{N} \frac{t}{3}\left(\frac{6(v-\lambda-k-r)}{6 \gamma+5 t}\right)^{2}-f
$$

Applying the free entry condition, the number of market makers, $N^{T}$, in the ABS market is the integer of the real number that satisfies the following condition:

$$
\frac{L}{N} \frac{t}{3}\left(\frac{6(v-\lambda-k-r)}{6 \gamma+5 t}\right)^{2}-f=0
$$




\section{A.3 Proof Lemma 2}

At the first stage, market makers maximize the following profit function for each of the ABS bonds they sell:

$$
\Pi_{i}=\left(p_{i}-k-q\right)\left(\frac{1}{L}-\delta+\frac{\left(p_{j}-p_{i}\right)}{t}\right), i=1, \ldots \ldots . ., L, j \neq i
$$

and where $j \neq i$ are the nearest ABS bonds to bond $i$.

Differentiating with respect to $p_{i}$, the first order condition becomes:

$$
\frac{\left(p_{j}-p_{i}\right)}{t}+\frac{1}{L}-\delta-\frac{1}{t}\left(p_{i}-k-q\right)=0
$$

By symmetry and working out the first order condition we obtain:

$$
p^{\circ}=k+q+t\left(\frac{1}{L}-\delta\right)
$$

If the second order condition is taken, we obtain:

$$
-\frac{2}{t}<0
$$

Therefore, $p^{0}$ are the prices that maximize profit functions for each of the ABS bonds.

At the second stage, and given $p^{0}$, the proportion of investors that buy ABS bonds can be determined. First, it is necessary to discover which investors are indifferent between buying a bond in the ABS market or in another alternative market. These indifferent investors, $x_{i} \quad i=1, \ldots, L$, hold the following condition:

$$
\begin{gathered}
v-\beta(N)-t x_{i}-p^{o}=0 \Rightarrow \\
\Rightarrow v-\beta(N)-t x_{i}-\left(k+q+t\left(\frac{1}{L}-\delta\right)\right)=0,
\end{gathered}
$$

where

$$
\delta=\frac{1}{L}-2 x_{i}
$$

Substituting the last expression in the equation that gives the indifferent consumers:

$$
\begin{aligned}
& v-\beta(N)-t x_{i}-k-q-2 t x_{i}=0 \Rightarrow \\
& \Rightarrow x_{i}^{T}=\frac{v-\beta(N)-k-q}{3 t} i=1, \ldots ., L .
\end{aligned}
$$

So, substituting $x_{i}$ in $\delta$, we obtain:

$$
\delta(v, N, k, q, t, L)=\frac{1}{L}-\frac{2(v-\beta(N)-k-q)}{3 t},
$$

and the demand for ABS from investors is at this stage: 


$$
d^{O}=\frac{2(v-\beta(N)-k-q)}{3 t} .
$$

Given $d^{\circ}$ and given the supply function of bonds:

$$
s=\frac{q-r}{\gamma}
$$

the equilibrium price that the ABS bond seller receives can be worked out:

$$
q^{\circ}=\frac{2 \gamma(v-\beta(N)-k)+3 t r}{2 \gamma+3 t}
$$

Subsisting $q^{\circ}$ in $p^{\circ}$ and $d^{\circ}$, the equilibrium final price and the demand for the ABS bonds are obtained:

$$
\begin{gathered}
p^{\circ}=\frac{2(\gamma+t)(v-\beta(N))+t(k+r)}{2 \gamma+3 t} \\
d^{\circ}=\frac{2(v-\beta(N)-k-r)}{2 \gamma+3 t} .
\end{gathered}
$$

As by assumption $\beta(N)$ could be binding its boundary, equilibrium price and demand could also be binding their boundaries:

$$
p^{o} \in\left[k+r, k+r+(\gamma+t) \frac{1}{L}\right] \text { and } d^{\circ} \in\left[0, \frac{1}{L}\right]
$$




\section{A.4 Proof Proposition 2}

It is assumed in the statement of the proposition that investors have the same search cost under both regimes, $\lambda$. Then, the market makers buying equilibrium prices are:

$$
q^{\circ}=\frac{2 \gamma(v-\lambda-k)+3 t r}{2 \gamma+3 t}
$$

under the opaque market, and

$$
q^{T}=\frac{6 \gamma(v-\lambda-k)+5 t r}{6 \gamma+5 t} .
$$

under the transparent market. So,

$$
\begin{gathered}
q^{O}<q^{T} \Rightarrow \\
\Rightarrow v-\lambda-k-r>0,
\end{gathered}
$$

condition which holds by assumption.

The traded equilibrium quantities are:

$$
d^{O}=\frac{2(v-\lambda-k-r)}{2 \gamma+3 t}
$$

under the opaque market, and

$$
d^{T}=\frac{6(v-\lambda-k-r)}{6 \gamma+5 t}
$$

under the transparent market. So,

$$
\begin{gathered}
d^{0}<d^{T} \Rightarrow \\
\Rightarrow 20 t(v-\lambda-k-r)>0,
\end{gathered}
$$

condition which holds, as $t$ and $(v-\lambda-k-r)$ are positive by assumption.

The market makers' equilibrium profits are:

$$
\Pi_{n}^{o}=\frac{L}{N} t\left(\frac{2(v-\lambda-k-r)}{2 \gamma+3 t}\right)^{2}-f
$$

under the opaque market, and

$$
\Pi_{n}^{T}=\frac{L}{N} \frac{t}{3}\left(\frac{6(v-\lambda-k-r)}{6 \gamma+5 t}\right)^{2}-f
$$

under the transparent market. So,

$$
\begin{gathered}
\Pi_{n}^{o}>\Pi_{n}^{T} \Rightarrow \\
\Rightarrow 24(4 \gamma+3 t)(v-\lambda-k-r)>0,
\end{gathered}
$$


condition which holds, as $t, \gamma$ and $(v-\lambda-k-r)$ are positive by assumption.

Finally, the market makers' mark-ups are:

$$
p^{O}-q^{O}-k=t d^{O}
$$

under the opaque market, and

$$
p^{T}-q^{T}-k=\frac{t}{3} d^{T}
$$

under the transparent market. So,

$$
\begin{gathered}
p^{0}-q^{0}-k>p^{T}-q^{T}-k \Rightarrow \\
6 \gamma+5 t>2 \gamma+3 t \Rightarrow \\
4 \gamma+2 t>0
\end{gathered}
$$

condition which holds, as $t$ and $\gamma$ are positive by assumption. 


\section{A.5 Proof Proposition 3}

The profit function of each of the market makers is:

$$
\Pi_{n}=\frac{L}{N}\left(p^{O}-k-q^{o}\right) d^{O}-f, n=1, \ldots ., N .
$$

where:

$$
\begin{gathered}
p^{o}=\frac{2(\gamma+t)(v-\beta(N))+t(k+r)}{2 \gamma+3 t}, \\
d^{o}=\frac{2(v-\beta(N)-k-r)}{2 \gamma+3 t},
\end{gathered}
$$

and

$$
q^{T}=\frac{2 \gamma(v-\beta(N)-k)+3 t r}{2 \gamma+3 t}
$$

Substituting $p^{\circ}, d^{\circ}$ and $q^{\circ}$ in the profit function, we obtain:

$$
\Pi_{n}=\frac{L}{N} t\left(\frac{2(v-\beta(N)-k-r)}{2 \gamma+3 t}\right)^{2}-f
$$

applying the free entry condition. The number of market makers, $N^{\circ}$, in the ABS market satisfies the following condition:

$$
\frac{L}{N} t\left(\frac{2(v-\beta(N)-k-r)}{2 \gamma+3 t}\right)^{2}-f=0
$$




\section{A.6 Proof Proposition 4}

The social welfare function is:

$$
W=L\left((v-\lambda-k-r) d-\frac{1}{4}(t+\gamma) d\right)-N f
$$

Under the assumption that $\beta(N)=\lambda$, the depth under transparency is:

$$
d^{T}=\frac{6(v-\lambda-k-r)}{5 t+6 \gamma}
$$

and

$$
d^{\circ}=\frac{2(v-\lambda-k-r)}{3 t+2 \gamma} .
$$

is the depth of the market under opacity. In proposition 2, it is proved that $d^{T}$ is higher than $d^{o}$ given parameters $v, \lambda, k, r, t$ and $\gamma$.

If we take Proposition 1 and 3, the number of market makers operating in the secondary ABS market is:

$$
N^{T} \geq 2
$$

such that

$$
\frac{L}{N} \frac{t}{3}\left(\frac{6(v-\lambda-k-r)}{6 \gamma+5 t}\right)^{2}-f=0
$$

under transparency, and

$$
N^{0} \geq 2
$$

such that

$$
\frac{L}{N} t\left(\frac{2(v-\beta(N)-k-r)}{2 \gamma+3 t}\right)^{2}-f=0
$$

under opacity. It is trivial to prove that $N^{T}<N^{O}$.

As the Social Welfare function is increasing in $d$ and decreasing in $N$, it is clear that Social Welfare is higher under transparency than under opacity. 
(whereby $v=100.5, B(2)=1, \lambda=1, k=0.2, r=99, \gamma=1, L=8, N=2$

and $f=0.005$ ).

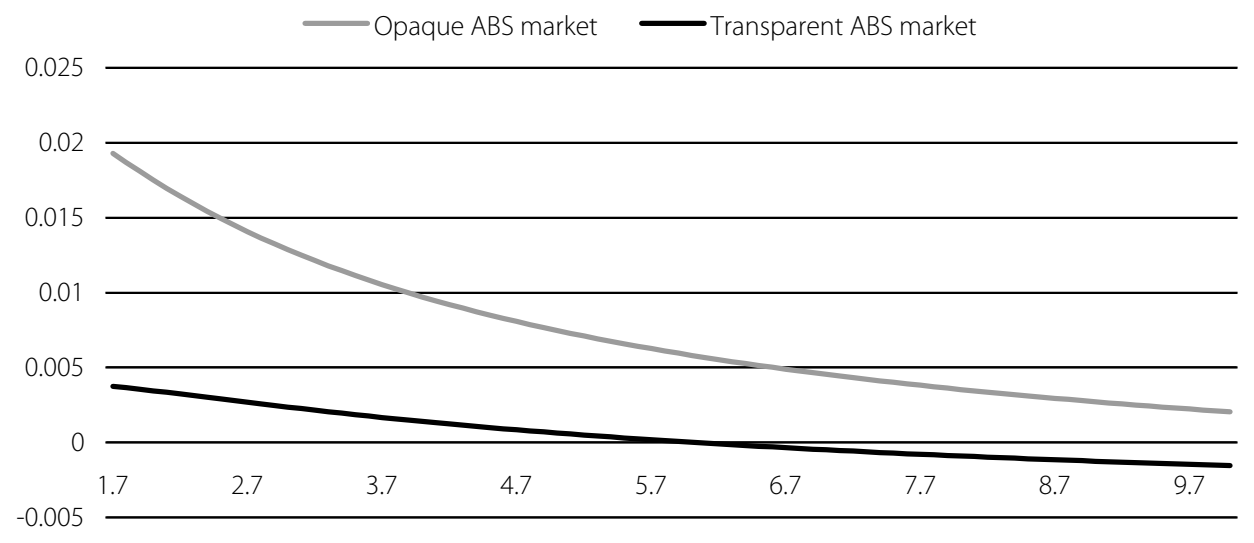

Social Welfare equilibrium paths values under different values of $\boldsymbol{t}$

(whereby $v=100.5, B(2)=1, \lambda=1, k=0.2, r=99, \gamma=1, L=8, N=2$

and $f=0.005$ ).

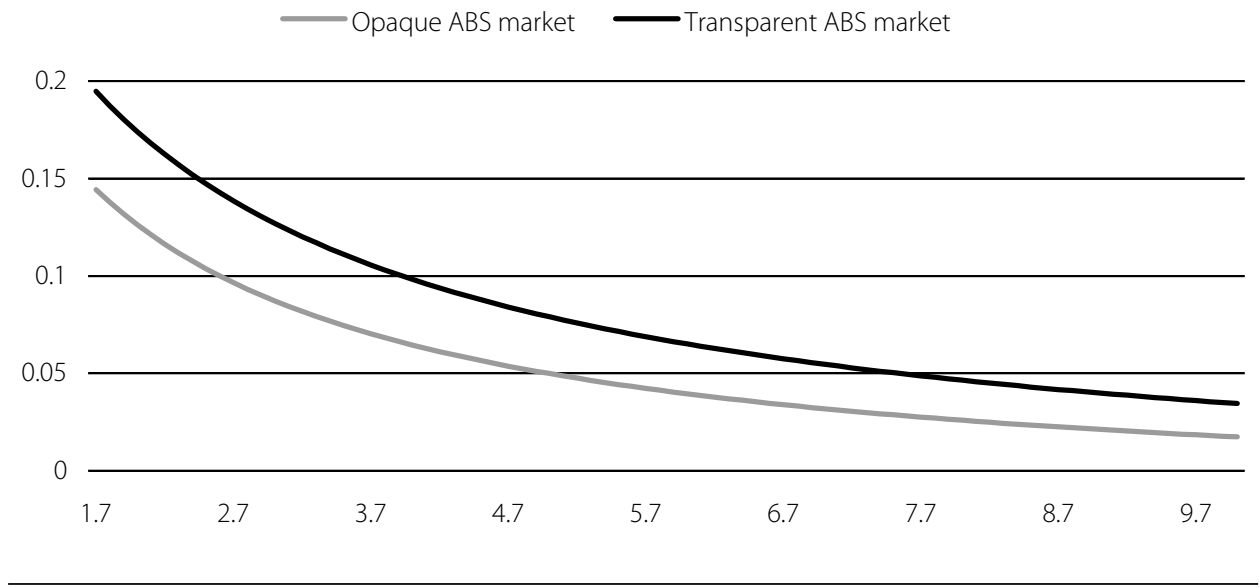



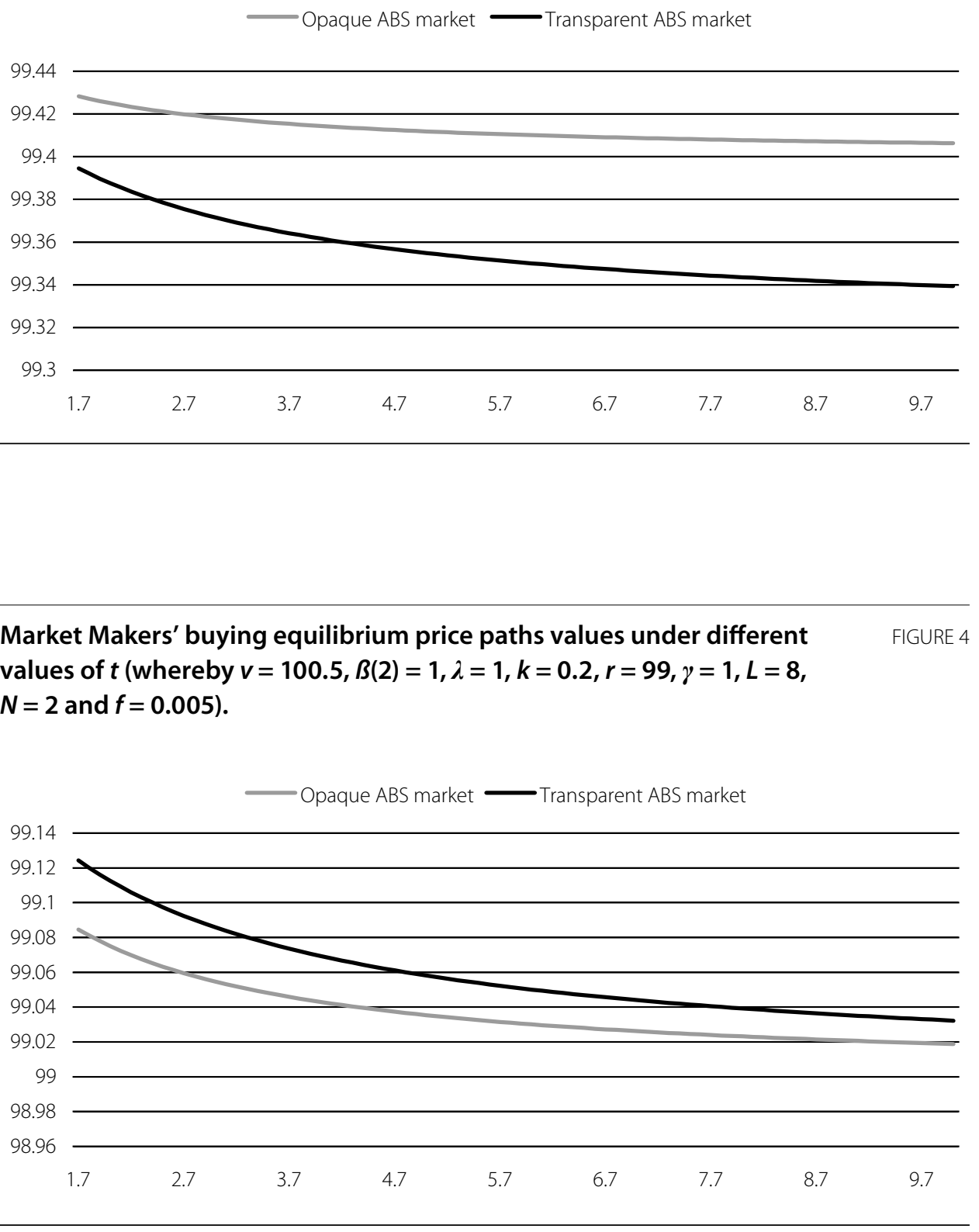

(whereby $v=100.5, B(2)=1, \lambda=1, k=0.2, r=99, \gamma=1, L=8, N=2$ and $f=0.005)$.

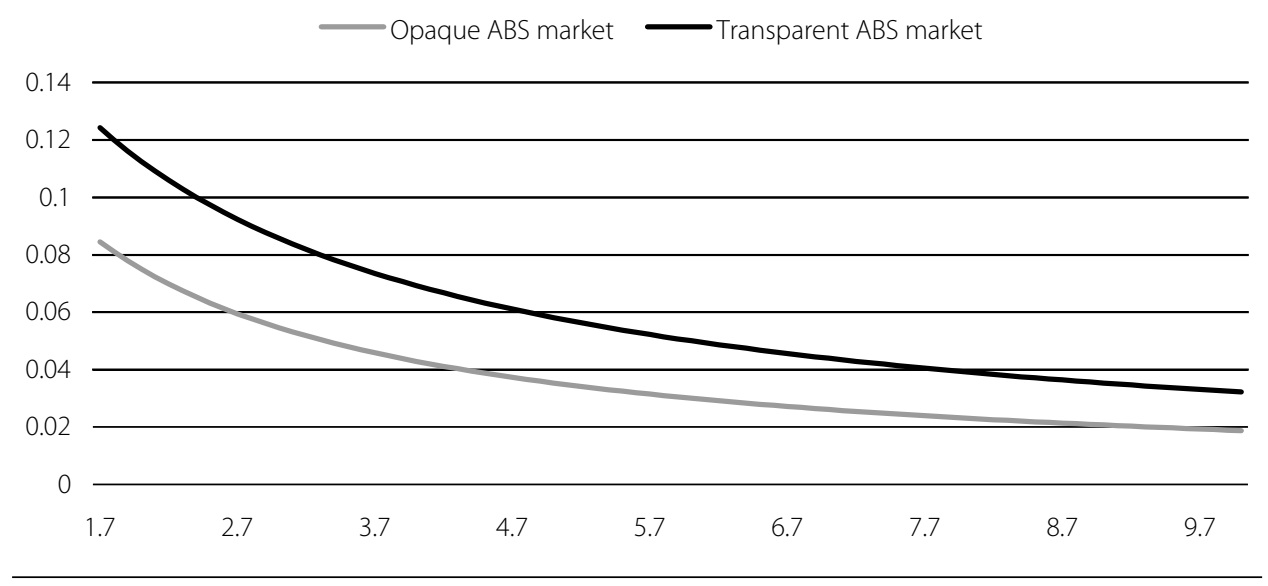

Market makers' equilibrium profit path under different values of $\gamma$ (whereby $v=100.5, B(2)=1, \lambda=1, k=0.2, r=99, t=2, L=8, N=2$ and $f=0.005$ ).

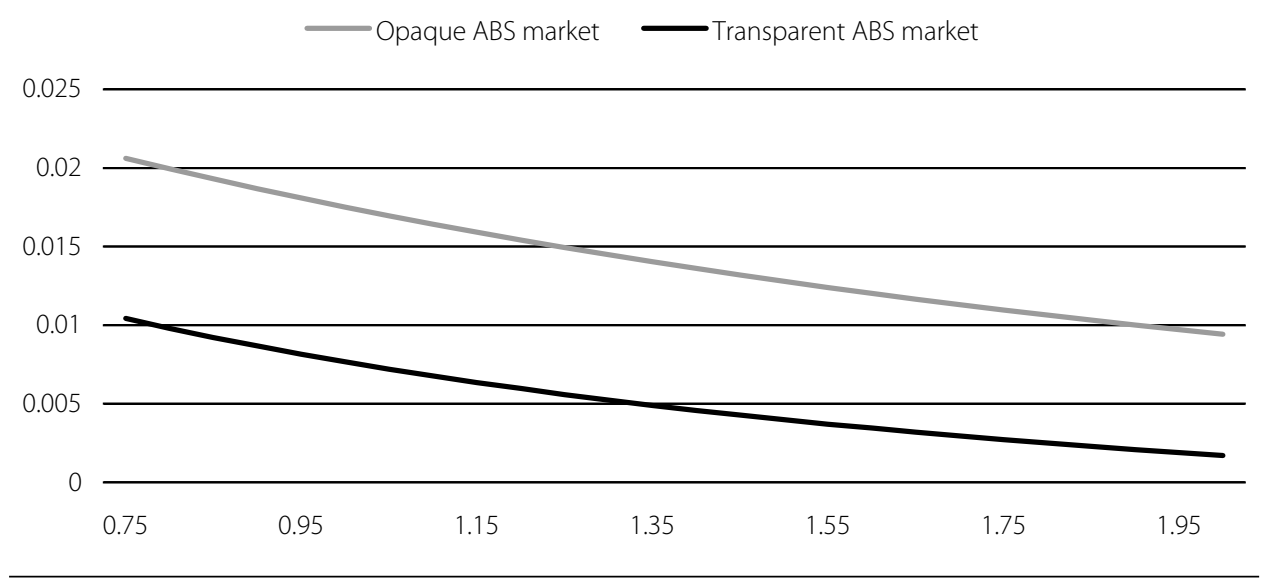




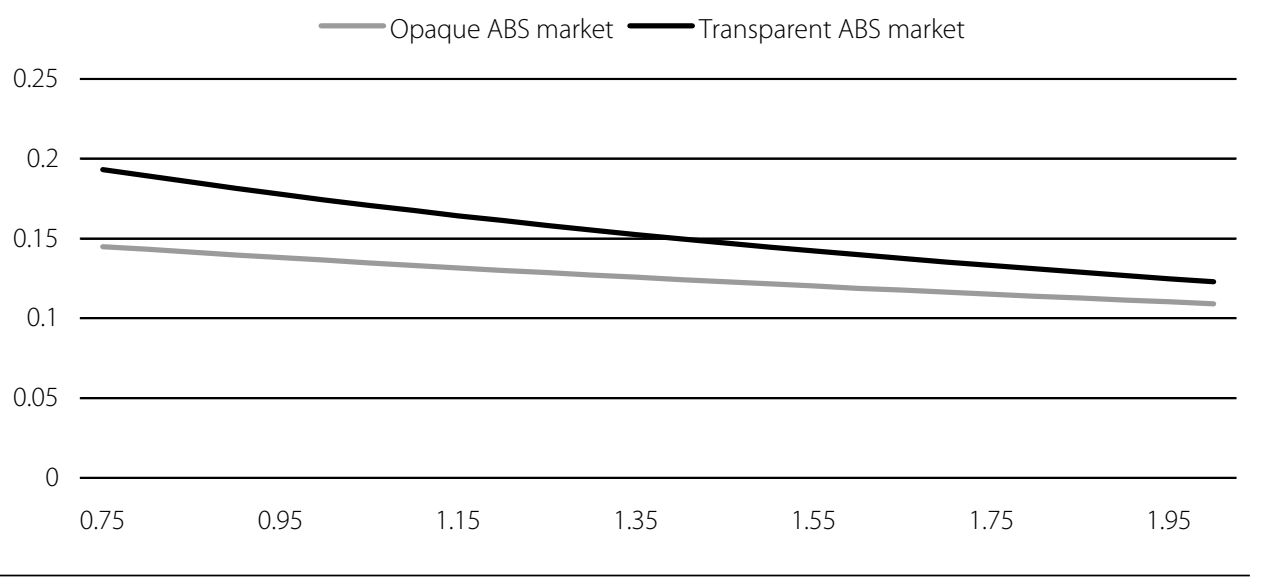

Market Makers' selling equilibrium price path values under different values of $\gamma$ (whereby $v=100.5, B(2)=1, \lambda=1, k=0.2, r=99, t=2, L=8$, $N=2$ and $f=0.005)$.

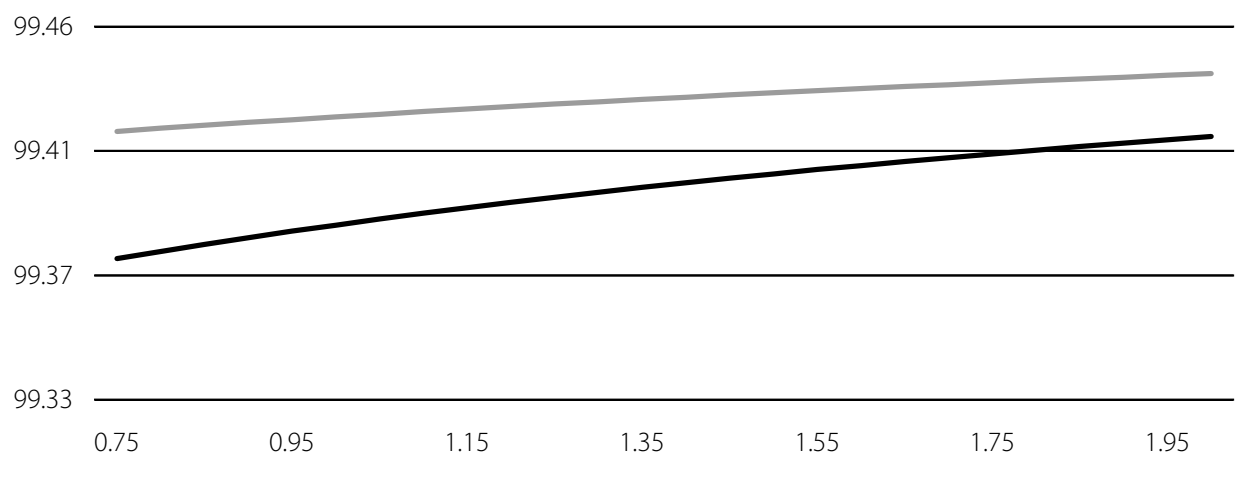



values of $\gamma$ (whereby $v=100.5, B(2)=1, \lambda=1, k=0.2, r=99, t=2, L=8$, $N=2$ and $f=0.005$ ).

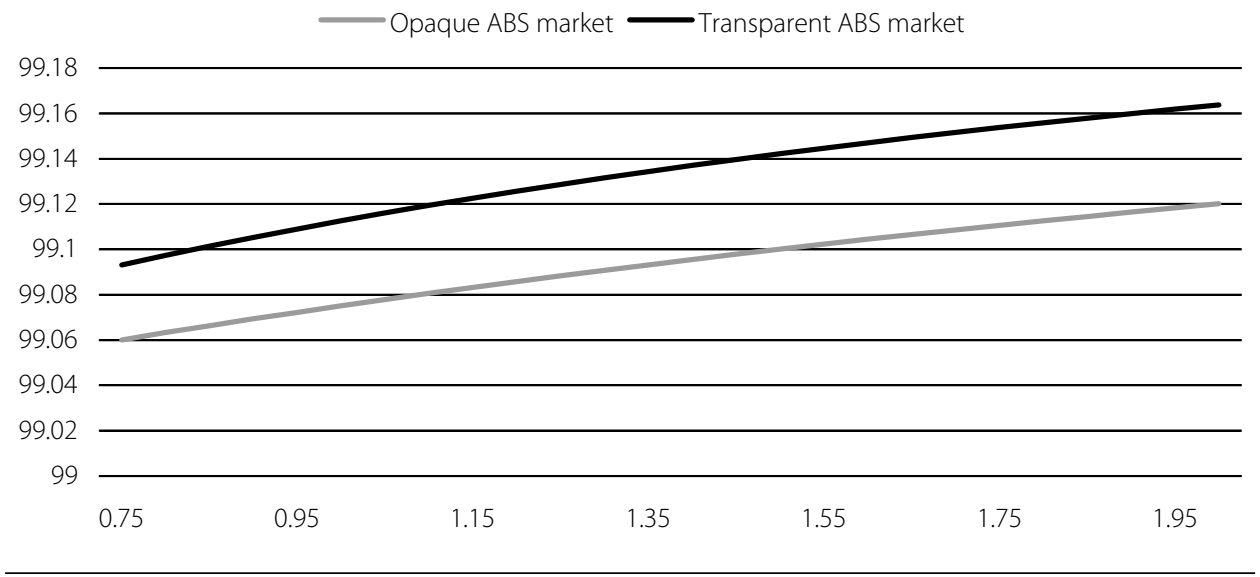

Depth of the ABS secondary market under different values of $\gamma$ (whereby $v=100.5, B(2)=1, \lambda=1, k=0.2, r=99, t=2, L=8, N=2$ and $f=0.005)$.

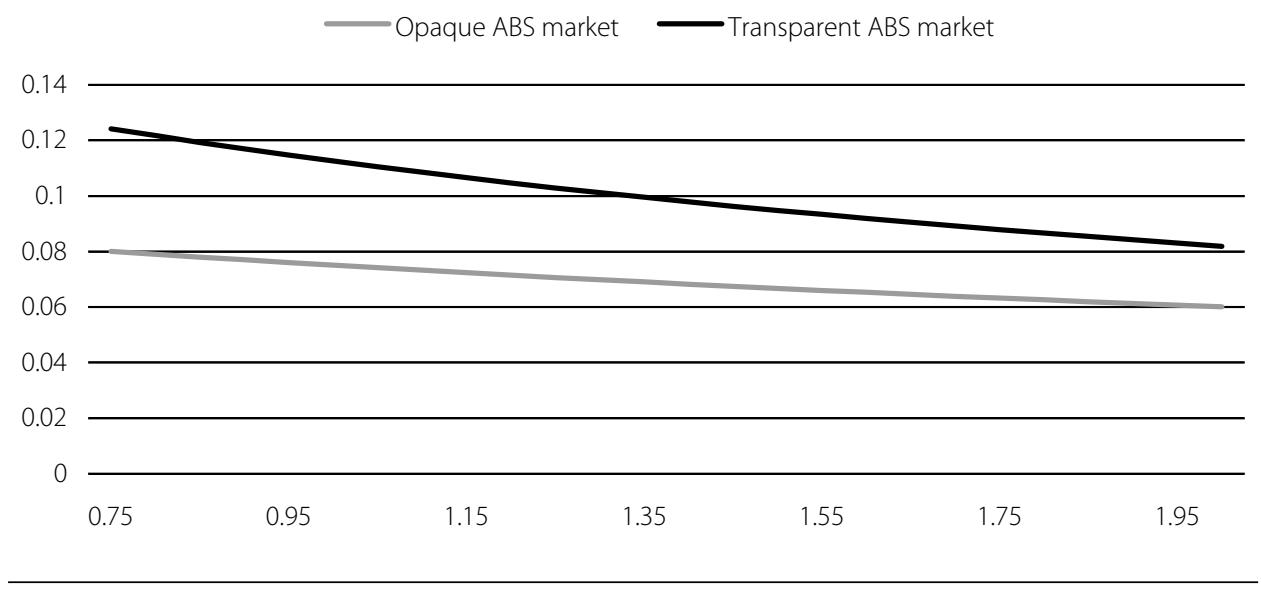



